\title{
Elderly patients in a general surgical unit: do they block beds?
}

\author{
DAVID GWYN SEYMOUR， ROBERT PRINGLE
}

\begin{abstract}
In a prospective study of patients aged 65 years and over admitted to a general surgical unit only one patient in 10 remained in hospital for more than a month and fewer than one patient in a hundred became a "bedblocker." While the over-65s had mean and median durations of stay which were longer than those of younger patients, in almost all cases a prolonged stay in hospital resulted from postoperative morbidity and was not related to social or administrative factors. Only a reduction in the incidence of postoperative morbidity could achieve a significant saving in the number of bed-days occupied by elderly people.
\end{abstract}

\section{Introduction}

In a survey of acute-hospital beds in three general hospitals in Liverpool, Rubin and Davies ${ }^{1}$ estimated that $4.8 \%$ of all beds were "blocked" by elderly patients who were no longer in need of inpatient medical or nursing care. Most of these "bedblockers" were waiting for alternative residential accommodation. In a survey of general surgical wards in England and Wales the mean duration of stay of patients aged 65 years and over was twice that of younger individuals. ${ }^{2}$

The present study assesses whether bed-blocking was the major factor prolonging the mean stay of elderly patients in a general surgical unit.

Royal Victoria Hospital, Dundee DD2 1SP

D G SEYMOUR, BSC, MRCP, senior registrar in geriatric medicine

Ninewells Hospital and Medical School, Dundee DD1 9SY R PRINGLE, CHM, FRCs, consultant surgeon

\section{Patients and methods}

A prospective study was made of patients aged 65 years and over who were admitted to a general surgical unit in Ninewells Teaching Hospital, Dundee. Information was collected about the reason for admission, type of operative or non-operative treatment, the social background, the major events of the stay in hospital, and the circumstances leading to discharge or death. The non-operative and operative mortality rates of these patients have been published. ${ }^{3}$ In line with earlier practice, ${ }^{14}$ bed-blockers were defined as surgical patients who had been in hospital for 31 days or more and who no longer required inpatient surgical treatment. A hospital stay of 31 days or more is referred to as "prolonged" in the present report.

In addition to this prospective data we obtained information from unit records about the duration of stay of patients aged between 15 and 64 years who were admitted to the unit on the same days as the older group. When a patient in this younger age group stayed in hospital for 31 days or over, a retrospective review was made of their case records to ascertain whether bed-blocking had occurred.

\section{Results}

GENERAL DATA

A total of 505 patients aged 65 and over were admitted, of whom 258 underwent surgery. The oldest patient admitted was 96 and the oldest patient having surgery 93. Emergency admissions made up $41.2 \%$ of the total. While the overall sex ratio of these patients was almost equal, in the small group aged 85 or over, 21 out of 27 patients were women.

During the same period, 574 men and 580 women aged between 15 and 64 were also admitted to the unit.

Of the patients aged over 65, 384 returned home, 73 died, 19 returned to institutional care, 13 were transferred to another acute specialty, 11 were sent for convalescence outside the Dundee area, and three entered a hospice for terminal care. Of the remaining two patients, one entered a residential home for the first time and the other was transferred to a geriatric rehabilitation ward from which she subsequently went home. 


\section{DURATION OF STAY}

\section{Mean duration of stay}

Table I gives the mean duration of stay of all groups of patients. There was a gradual increase in the mean duration of stay with age, which became more pronounced in the groups aged 65 and over. The mean duration of stay of all the over-65s taken together was about twice that of younger patients, as found in previous surveys. ${ }^{2}$ As the distribution pattern of the duration of stay was appreciably skewed, no confidence limits have been calculated in table $I$.

TABLE I-Mean duration of stay in hospital of surgical patients

\begin{tabular}{lcccccc}
\hline \multirow{2}{*}{ Age group } & \multicolumn{2}{c}{ Men } & & \multicolumn{2}{c}{ Women } \\
\cline { 2 - 3 } \cline { 5 - 6 } & $\begin{array}{c}\text { No of } \\
\text { patients }\end{array}$ & $\begin{array}{c}\text { Mean stay } \\
\text { (days) }\end{array}$ & & $\begin{array}{c}\text { No of } \\
\text { patients }\end{array}$ & $\begin{array}{c}\text { Mean stay } \\
\text { (days) }\end{array}$ \\
\hline Over 75 & 94 & $14 \cdot 9$ & & 117 & $18 \cdot 0$ \\
65 to 74 & 167 & $13 \cdot 1$ & & 127 & $16 \cdot 0$ \\
55 to 64 & 154 & $8 \cdot 6$ & & 148 & $10 \cdot 0$ \\
45 to 54 & 134 & $7 \cdot 6$ & & 119 & $6 \cdot 7$ \\
35 to 44 & 92 & $6 \cdot 4$ & & 133 & $6 \cdot 6$ \\
25 to 34 & 100 & $6 \cdot 2$ & & 92 & $7 \cdot 3$ \\
15 to 24 & 94 & $5 \cdot 3$ & & 88 & $4 \cdot 5$ \\
All patients $\geqslant 65$ & 261 & 13.7 & & 244 & $17 \cdot 0$ \\
Patients aged 15-64 & 574 & $7 \cdot 1$ & & 580 & $7 \cdot 3$ \\
\hline All patients & 835 & $9 \cdot 15$ & & 824 & $10 \cdot 14$ \\
\hline
\end{tabular}

\section{Median duration of stay}

The mean duration of stay is particularly sensitive to the effect of a prolonged stay in hospital in a handful of patients, as a population mean value is greatly influenced by a few outlying results. ${ }^{5}$ The median duration of stay, on the other hand, is much less affected by such outlying values ${ }^{6}$ and thus may be used to minimise their influence. It is also possible to construct non-parametric $95 \%$ confidence limits for the median, even when the population is skewed. ${ }^{5}$

The figure shows that the median duration of hospital stay, unlike the mean, did not rise significantly between the ages 25 to 64 in men and 25 to 54 in women. A pronounced rise was still seen, however, after the age of 65 , and the difference between the median duration of stay of patients aged under 64 and those aged over 65 was highly statistically significant ( $p<0.001$ using the non-parametric MannWhitney test). The median stay of women was higher than that of men in all age groups but attained statistical significance $(p<0.05)$ only in the group aged from 65 to 74 .

TABLE II-Prolonged hospital stay and age

\begin{tabular}{|c|c|c|c|}
\hline \multirow{3}{*}{ Age group } & \multicolumn{3}{|c|}{ Duration of hospital stay } \\
\hline & \multirow{2}{*}{$\frac{0 \text { to } 30 \text { days }}{\text { No of patients }}$} & \multicolumn{2}{|c|}{31 days or more } \\
\hline & & No of patients & $\%$ of age group \\
\hline $\begin{array}{l}\text { Over } 75 \\
65 \text { to } 74 \\
55 \text { to } 64 \\
45 \text { to } 54 \\
35 \text { to } 44 \\
25 \text { to } 34 \\
15 \text { to } 24\end{array}$ & $\begin{array}{l}189 \\
264 \\
291 \\
249 \\
225 \\
190 \\
182\end{array}$ & $\begin{array}{r}22 \\
30 \\
11 \\
4 \\
0 \\
2 \\
0\end{array}$ & $\begin{array}{r}10.4 \\
10.2 \\
3.6 \\
1.6 \\
0.0 \\
1.0 \\
0.0\end{array}$ \\
\hline All patients & 1590 & 69 & $4 \cdot 2$ \\
\hline
\end{tabular}

$(7 \times 2$ Chi-squared analysis $=74 \cdot 6, \mathrm{p}<0.001$.
Patients with a prolonged stay in hospital

To satisfy the criteria for bed-blocking of Rubin and Davies ${ }^{1}$ a patient requires to have been in hospital for more than a month, and to be no longer in need of medical or nursing care in that environment. Table II therefore identifies those 69 patients $(4.2 \%$ of all patients admitted) who fulfilled the first of these two criteria by staying in hospital for 31 days or more. Fifty-two of the 69 patients $(24$ men, $\bar{J}$ 28 women) were over 65 , and this predominance of elderly people गु among patients staying in hospital for more than 31 days is shown $\infty$ formally by the high value of the Chi-squared statistic in table II.

As a stay in hospital of 31 days or more does not by itself constitute bed-blocking, the principal reason for the prolonged period in hospital $\vec{\equiv}$ of each of these 69 patients was examined (table III). Social or $\stackrel{\oplus}{\rightarrow}$ administrative factors were the reason for the prolonged stay in only four patients - that is, only four bed-blockers were encountered in $\underline{\sigma}$ the whole study. All four were women over 65 . One, aged 93, spent $\overline{\frac{S}{D}}$ 98 days in hospital waiting for a place in a residential home for the elderly after the successful resolution of her surgical problem. The other three women, all over 75 , lived alone with very little support. क All three could have left hospital about a month earlier if home $\overrightarrow{0}$ circumstances had been more favourable.

Thus social or administrative factors were not the reason for the $\overrightarrow{\vec{\omega}}$ prolonged admission in most elderly general surgical patients studied. As table III shows, the commonest reason for delay in discharge, in young and old patients alike, was a postoperative surgical or medical complication. Wound complications alone accounted for a fifth of the $\infty$ cases of a prolonged stay in hospital in the over- $65 \mathrm{~s}$, and almost onehalf of such cases in younger patients.

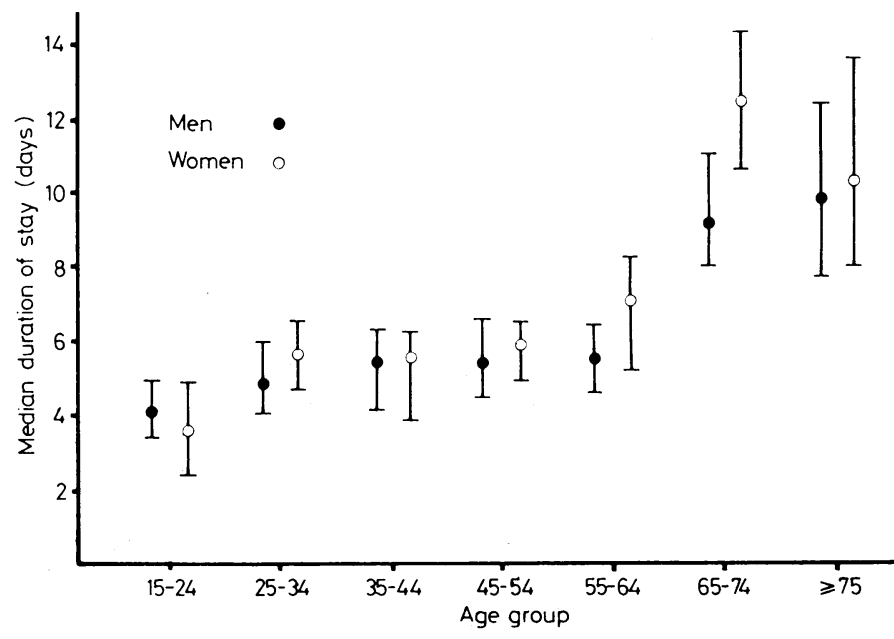

Age and median duration of stay (with $95 \%$ confidence limits).

Eleven patients, nine of them over 65 , required prolonged support $\delta$ in hospital because of advanced malignancy. They were regarded as "appropriately placed" as none was fit for discharge, and all required $ᄋ$ some form of surgical or specialised nursing care.

Nine patients were in hospital for more than 61 days and six of $\mathscr{N}$ these (two men, four women) were over 65 . In only one of the nine $\rightarrow$ patients (the woman of 93 already described) was there evidence of bed-blocking. The longest stay in hospital of all was a woman of $77 \mathrm{~N}$ with advanced rheumatoid arthritis who had prolonged pelvic and N

TABLE III-Principal reason for prolonged stay in hospital of 69 patients

\begin{tabular}{|c|c|c|c|c|c|c|c|c|}
\hline & \multirow{2}{*}{$\begin{array}{l}\text { Prolonged } \\
\text { preoperative } \\
\text { stay } \\
\text { (over } 7 \text { days) }\end{array}$} & \multicolumn{3}{|c|}{ Postoperative complications } & \multirow{2}{*}{$\begin{array}{l}\text { Repeat } \\
\text { surgery }\end{array}$} & \multirow{2}{*}{ Malignancy } & \multirow[b]{2}{*}{$\begin{array}{l}\text { Social or } \\
\text { administrative } \\
\text { factors }\end{array}$} & \multirow[b]{2}{*}{$\begin{array}{c}\text { Others } \\
\text { (all non-socia } \\
\text { factors) }\end{array}$} \\
\hline group & & Wound & $\begin{array}{c}\text { Other } \\
\text { surgical }\end{array}$ & Medical & & & & \\
\hline \multirow[t]{2}{*}{ 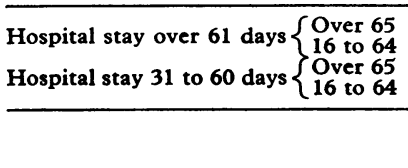 } & $\begin{array}{l}0 \\
0 \\
7 \\
1\end{array}$ & $\begin{array}{l}2 \\
1 \\
9 \\
7\end{array}$ & $\begin{array}{l}\mathbf{0} \\
\mathbf{0} \\
\mathbf{3} \\
\mathbf{1}\end{array}$ & $\begin{array}{l}\mathbf{0} \\
0 \\
\mathbf{9} \\
\mathbf{1} \\
\end{array}$ & $\begin{array}{l}1 \\
1 \\
5 \\
2 \\
\end{array}$ & $\begin{array}{l}1 \\
1 \\
8 \\
1\end{array}$ & $\begin{array}{l}1 \\
0 \\
3 \\
0\end{array}$ & $\begin{array}{l}1 \\
0 \\
2 \\
1\end{array}$ \\
\hline & $\begin{array}{c}8 \\
(11.6 \%)\end{array}$ & $\begin{array}{c}19 \\
(27 \cdot 5 \%)\end{array}$ & $\begin{array}{c}4 \\
(5 \cdot 8 \%)\end{array}$ & $\begin{array}{c}10 \\
(14.5 \%)\end{array}$ & $\begin{array}{c}9 \\
(13.0 \%)\end{array}$ & $\begin{array}{c}11 \\
(15 \cdot 9 \%)\end{array}$ & $\begin{array}{c}4 \\
(5 \cdot 8 \%)\end{array}$ & $\begin{array}{c}4 \\
(5 \cdot 8 \%)\end{array}$ \\
\hline
\end{tabular}


wound sepsis after a faecal peritonitis. She eventually died in hospital after 269 days. This unfortunate patient required repeated minor surgical procedures and wound dressings and was not regarded as having blocked a bed, despite the duration of her stay in hospital.

\section{Discussion}

The definition of a bed-blocker used in the present study is based on that of Rubin and Davies - that is, a patient staying in hospital for more than a month who no longer requires inpatient nursing or medical care in that environment. Nevertheless, the amount of bed-blocking we found among elderly general surgical patients was much less than that encountered among the elderly medical and surgical patients of the above authors. ${ }^{1}$ Only one in 10 of our patients who were 65 or more stayed in hospital over 31 days, and fewer than $1 \%$ of the over65 s became bed-blockers. Even in surgical patients aged 85 and over only two out of the 27 admitted were still in hospital after 31 days, and only one became a bed-blocker. In contrast, Rubin and Davies ${ }^{1}$ reported that just under $9 \%$ of all patients aged 60 and over in their study were blocking acute beds at the time of their survey.

Rubin and Davies ${ }^{1}$ concluded that increased residential and community services outside hospital would significantly reduce the number of acute-hospital beds that became blocked by elderly patients. Our study indicates that the same cannot be said of general surgical beds. When a prolonged stay in hospital occurred among our elderly general surgical patients, in 48 out of 52 cases there were good medical or surgical reasons for the patient remaining in hospital. Methods by which these medical and surgical factors could be modified to reduce mean hospital stay are considered below.

Our results strongly suggest that a reduction in the surgical type of postoperative complication, particularly sepsis, would greatly reduce mean hospital stay in young and old patients alike. Research into the prophylactic use of the newer antibiotics is encouraging in this respect. ${ }^{7} \mathrm{~A}$ reduction in the medical type of postoperative complication might be achieved by more sophisticated methods of preoperative assessment, ${ }^{8}$ although such methods are difficult to apply in emergency cases, where the risk of morbidity is greatest (Seymour DG, Pringle $R$, unpublished observations).

A reduction in the time spent on inpatient preoperative assessment might reduce mean hospital stay on surgical units dealing primarily with elective patients. In the present study, however, there were only seven elderly patients in whom a long period of preoperative assessment accounted for a prolonged hospital stay, and in each case there were reasons for preferring the preoperative assessment to be carried out as an inpatient.

In areas without hospice facilities for terminal care, bedblocking can occur because patients with advanced malignancies must remain in the surgical ward. ${ }^{9}$ This was not so in the general surgical unit under study.

We conclude that, in the general surgical unit investigated, only a reduction in the incidence of postoperative morbidity could achieve a significant saving in the number of bed-days occupied by elderly people.

We have used a hospital stay of 31 days or more as one of our two criteria for identifying a bed-blocker. This figure, which is practically identical with that used by previous authors, ${ }^{1}$ is convenient both because it isolates a relatively small number of patients for analysis, and because the reason for the delay in discharge has usually become apparent by the fifth week of the admission. To a health planner interested in identifying future hospital and community needs, however, the arbitrary figure of 31 days is of much less relevance. This may be illustrated with data from the present study. While patients over 65 had a mean duration of stay on the surgical unit that was twice that of younger patients, $90 \%$ of the elderly group still left hospital in the first four weeks, and therefore fell outside the definition of bed-blocking used in this and previous studies. Even when patients with a prolonged stay in hospital were virtually excluded from the analysis by the statistical device of using the median in place of the mean stay, older patients still remained in hospital significantly longer than the young.

A complete study of the reasons that lengthen the mean hospital stay of elderly surgical patients could not therefore confine itself to the small number of patients who remained in hospital for more than four weeks. Instead, it would need to study all adult surgical admissions prospectively to weigh up the relative contributions to hospital stay made by age, preoperative preparation, and medical, surgical, and social factors. This would be a formidable undertaking but would prove a valuable tool for forward planning.

We thank Dr E J H Moore for his very helpful comments and Professor Peter Sprent for statistical advice.

\section{References}

1 Rubin SG, Davies GH. Bed blocking by elderly patients in generalhospital wards. Age Ageing 1975;4:142-7.

2 Medical Manpower Steering Group. Developments in health services for the elderly-implications for medical manpower. London: HMSO, 1980.

${ }^{3}$ Seymour DG, Pringle R. A new method. of auditing surgical mortality rates: application to a group of elderly general surgical patients. $\mathrm{Br} \mathrm{Med}$ f $1982 ; 284$ : 1539-42.

${ }^{4}$ Anonymous. Blocked beds. Lancet 1980;ii:1013.

${ }^{5}$ Snedecor GW, Cochran WG. Statistical methods. 7th ed. Ames, Iowa: Iowa State University Press, 1980.

${ }^{6}$ Burley LE, Currie CT, Smith RG, Williamson J. Contribution from geriatric medicine within acute medical wards. Br Med f 1979;ii:90-2.

${ }^{7}$ Keighley MRB. Prophylactic antibiotics in surgery. Br 7 Hosp Med 1980 23: $465-72$

${ }^{8}$ Del Guercio LRM, Cohn JD. Monitoring operative risk in the elderly. FAMA 1980;243:1350-5.

${ }^{9}$ Gough MH, Kettlewell MGW, Marks CG, Holmes SJK, Holderness J. Audit: an annual assessment of the work and performance of a surgical firm in a regional teaching hospital. $B r M e d \mathcal{F} 1980 ; 281: 913-8$.

(Accepted 23 April 1982)

Some veterinary surgeons recommend that cats should be dewormed for roundworms and tapeworms quarterly and tablets are available for these purposes. Are these precautions sufficient to prevent transmission to man?

The transmission to man of round or tapeworm infestation from cats is a theoretical possibility, but on practical grounds the chance of this event occurring is very slight indeed. The tapeworm Dipylidium caninum is transmitted by the cat ingesting infected fleas; it will then take about two months from eating a flea to get mature worms. The eggs passed by the worms are only infective to larval fleas and not to man. There are very rare reports of children having adult $D$ caninum, and they must have become infected by eating cat fleas, but it must be emphasised that there were no clinical signs. Taenia taeniaformis, transmitted by eating mice, is not infective to man. Only one group of cat roundworms is of any potential danger to man, and the important members of this group are Toxocara cati and Toxascaris leonina. Cats are infected mainly by eating mice, and it takes six weeks for the worms to reach the adult stage. Theoretically one should therefore dose every six weeks, but not all drugs are effective against the early larval stages. It is agreed, however, that $T$ cati is nothing like as important as $T$ canis (a dog roundworm) in causing human visceral larva migrans, and cats provide very unlikely sources of infestation for man. The worm eggs would have to develop for two to four weeks on the ground, and cats are fastidious and always bury their faeces. One could always theorise that cat faeces could contaminate fresh lettuce, for instance. In summary, the cat presents little hazard to man in respect of tape and roundworm infestation. Current data sheets for treating tapeworm infestation in cats indicate regular treatment at monthly intervals where there is a possibility of reinfestation, and for roundworms numerous effective products are available for regular use if the risk of reinfestation is high.-J R WALTON, senior lecturer in veterinary preventive medicine, Liverpool. 